\title{
REVIEW
}

\section{Energy-based devices for treatment of melasma}

\author{
Juliana Merheb Jordão ${ }^{1 *}$, Priscila Regina Orso Rebellato ${ }^{2}$ \\ ${ }^{1}$ Department of Laser Therapy, Hospital Evangélico de Curitiba, Faculdade Evangélica de Curitiba, Curitiba, Brazil \\ ${ }^{2}$ Department of Trichology, Cosmiatry and Laser, Hospital Evangélico de Curitiba, Faculdade Evangélica de Curitiba, Curitiba, Brazil
}

\begin{abstract}
Melasma, as a pigmentation disorder, induces significant stress to the patients and its recurrent nature remains a challenge in clinical practice. Treatment is based on a variety of mechanisms to prevent and/or stop the pigment production process by destroying the deposited pigment for removal or release, by peeling cells to improve their turnover, and by reducing inflammation. The use of appropriate devices and correct settings are crucial in the treatment of melasma. Cases unresponsive to topical bleaches or chemical peels should be referred for laser therapy. It is important that a maintenance therapy to avoid the recurrence of melasma be indicated. In this paper, we review energy-based devices for melasma treatment.

Keywords: Lasers; melasma treatment

Citation: Jordão JM and Rebellato PRO. Energy-based devices for treatment of melasma. J Surg Dermatol 2017; 2(T1): 130-138; http://dx.doi.org/10.18282/jsd.v2.it1.148.
\end{abstract}

*Correspondence to: Juliana Merheb Jordão, Department of Laser Therapy, Hospital Evangélico de Curitiba, Faculdade Evangélica de Curitiba, Curitiba, Brazil, dra.julianajordao@hotmail.com.

Received: $21^{\text {st }}$ March 2017; Accepted: $12^{\text {th }}$ April 2017; Published Online: $26^{\text {th }}$ April 2017

\section{Introduction}

Melasma is an acquired, generally symmetric, pigment disorder that appears as irregular macules and patches usually on the face, ranging from light- to dark-brown. It is commonly seen in fertile aged and darker-skinned women. The disease is prevalent in East Asians, Hispanics and in Indo-Chinese origin people who reside in locations with high-intensity ultraviolet (UV) radiation.

Contributing factors include UV exposure, pregnancy, hormonal variations, genetic inheritance, thyroid pathologies, the use of oral contraceptive or antiepileptic medicaments, and contact with irritant cosmetics. An elevated melanocyte activity seems to be the basic pathogenesis.

The negative impact of melasma in the patient's life quality is very relevant. Treatments tend to be disappointing due to their relapsing nature, controversial therapies offering controls, and few preventative options.

Therapeutic alternatives include photoprotection, topical bleaches, and, increasingly, energy-based technolo- gies. A number of lasers and light sources have been analyzed in the treatment of melasma, offering broadly varied results.

\section{Melasma and energy-based devices}

Melasma is a pigmentation disorder prevalent in sun-exposed areas, and is characterized by symmetrically distributed dark macules and patches. There are three classified clinical patterns: centrofacial (most common), malar, and mandibular. According to Wood's light examination and histology, melasma can be epidermal, dermal, and mixed ${ }^{[1-3]}$.

Despite the fact that melasma pathogenesis is not well understood, the most universally accepted cause is a hyperactivity of melanocytes when stimulated by UV light exposure. This situation leads to an increased tyrosine-mediated melanogenesis, and the melanosomes are transferred to epidermal keratinocytes ${ }^{[4]}$. Genetics, hormones/endocrinopathies, and photosensitizing medications also act and contribute to UV sensitivity. Estrogen, 
related to pregnancy or to oral contraceptive pills, induces the melanocyte-stimulating hormone (MSH) discharge by stimulating tyrosinase, which explains the large number of cases in females ${ }^{[4-6]}$.

There are actually no guidelines for the treatment of melasma ${ }^{[7]}$. As a current rule, sun avoidance and appropriate application of UVA- and UVB-blocking agents are counseled to patients ${ }^{[8]}$. First-line therapy consists of bleaching agents and broad-spectrum sunscreens, especially fixed triple combinations (e.g., hydroquinone $4 \%$, tretinoin $0.05 \%$, and fluocinolone acetonide $0.01 \%$ ). For the second-line therapy, there are applications of chemical peeling agents. The third-line therapy is the use of technology, including laser modalities and intense pulsed light (IPL) $)^{[2,9]}$. The major disadvantages of topical agents are the need for long-term utilization and the gradual or limited treatment responses. Furthermore, while topical therapies may be effective for epidermal melasma, it is noticed that dermal and mixed types are commonly refractory to topical monotherapy because of their deeper pigments. Energy-based devices appear as alternatives to help dealing with resistant melasma circumstances $^{[10]}$.

Lasers have transformed the treatment of many conditions in dermatology, as well as in pigmentary pathologies. Despite the fact that many pigmentary disorders have obtained good results with this modality, the safety and efficacy of lasers for melasma is, till now, controversial $^{[11,12]}$.

Laser devices are often employed to treat pigmentary disorders through their photothermal, photomechanical, and ablative effects. The principle of photothermolysis dictates that the target molecule, the chromophore, should preferentially absorb the delivered wavelength of light, and that the light energy must be delivered over a period of time to damage the target while limiting collateral damage to adjacent structures ${ }^{[13,14]}$.

When targeting melanin, dermatologists must utilize a selective window between 630 and $1,100 \mathrm{~nm}$, where a good skin penetration is reached and there is a preferential absorption of melanin over oxyhaemoglobin. The absorption of melanin decreases as wavelength increases, but a longer wavelength results in deeper skin penetration. Shorter wavelengths $(<600 \mathrm{~nm})$ destroy pigmented cells with lower energy fluences, while longer wavelengths $(>600 \mathrm{~nm})$ penetrate deeper and need more energy to induce melanosome destruction ${ }^{[11]}$.

Pigment specificity of lasers also depends on pulse width. With an approximated thermal relaxation time (TRT) of 250-1000 ns, melanosomes demand sub-microsecond laser pulses $(<1 \mu \mathrm{s})$ for their selective damage; however, longer pulse durations in the millisecond domain do not induce specific melanosome destruction $^{[13]}$.

\section{Q-switched lasers}

Q-switched Alexandrite, Q-switched Neodymium-doped yttrium aluminium garnet (Nd:YAG) and Q-switched Ruby lasers target melanosome with pulse durations in the nanosecond range. These short pulse targets the small chromophore of melanin and generates photoacoustic effect that leads to melanin destruction ${ }^{[11-16]}$.

The threshold for the photoacoustic damage of skin by Q-switched Nd:YAG laser (QSNY) light is between $1.6-5 \mathrm{~J} / \mathrm{cm}^{2}$, which indicates that pigment destruction can occur without skin ablation. So, this modality is selective (targeting pigmented structures) and it is non-ablative (being below the photo-acoustic threshold). This effect justifies the idea that the improvement of melasma by sub-thermolytic QSNY light is due to the selectivity of this light on a sub-cellular level, as it destroys exclusively pigments and not cells, hence being named "sub cellular, selective thermolysis"

"Laser toning" is a technique that has become increasingly popular. It involves 1064-nm QSNY low fluences $\left(1.6-3.5 \mathrm{~J} / \mathrm{cm}^{2}\right)$, large spot sizes $(6-8 \mathrm{~mm})$, and multiple passes, and it is performed in 5-10 sessions at weekly to monthly intervals (Figure 1) ${ }^{[13,16]}$. Parra and co-workers studied 16 Brazilian women (Fitzpatrick III-IV) who had mild to severe facial melasma. They were treated only with 1064-nm QSNY at one-week intervals for 10 weeks $\left(8-\mathrm{mm}\right.$ spot size, $0.8-1.6 \mathrm{~J} / \mathrm{cm}^{2}$ of fluence and $10-\mathrm{Hz}$ pulse repetition rate). The results showed a statistically significant improvement one week after the treatment and at day 30 . However, no significant improvement was observed at day 90 or at day 180 compared to baseline. By the six-month follow up, similar rates of recurrence and maintenance of improvement were observed ${ }^{[17]}$.

Jeong and co-workers performed a split-face crossover study on 13 patients of Fitzpatrick phototypes III and IV where Q-switched (QS) 1064-nm laser therapy (7 mm, $1.6-2.0 \mathrm{~J} / \mathrm{cm}^{2}$ and 2 passes) was contrasted with pre- or post-treatment with triple combination (TC) cream (4\% hydroquinone, $0.05 \%$ Tretinoin, and $0.01 \%$ fluocinolone acetonide). The authors noticed that when laser treatment was used after eight weeks of topical treatment, better results than before were obtained ${ }^{[18]}$.

Wattanakrai and co-workers developed a split-face trial on 22 patients with dermal- or mixed-type melasma, in which they compared treatment using sub-thermolytic QSNY and topical 2\% hydroquinone with treatment 


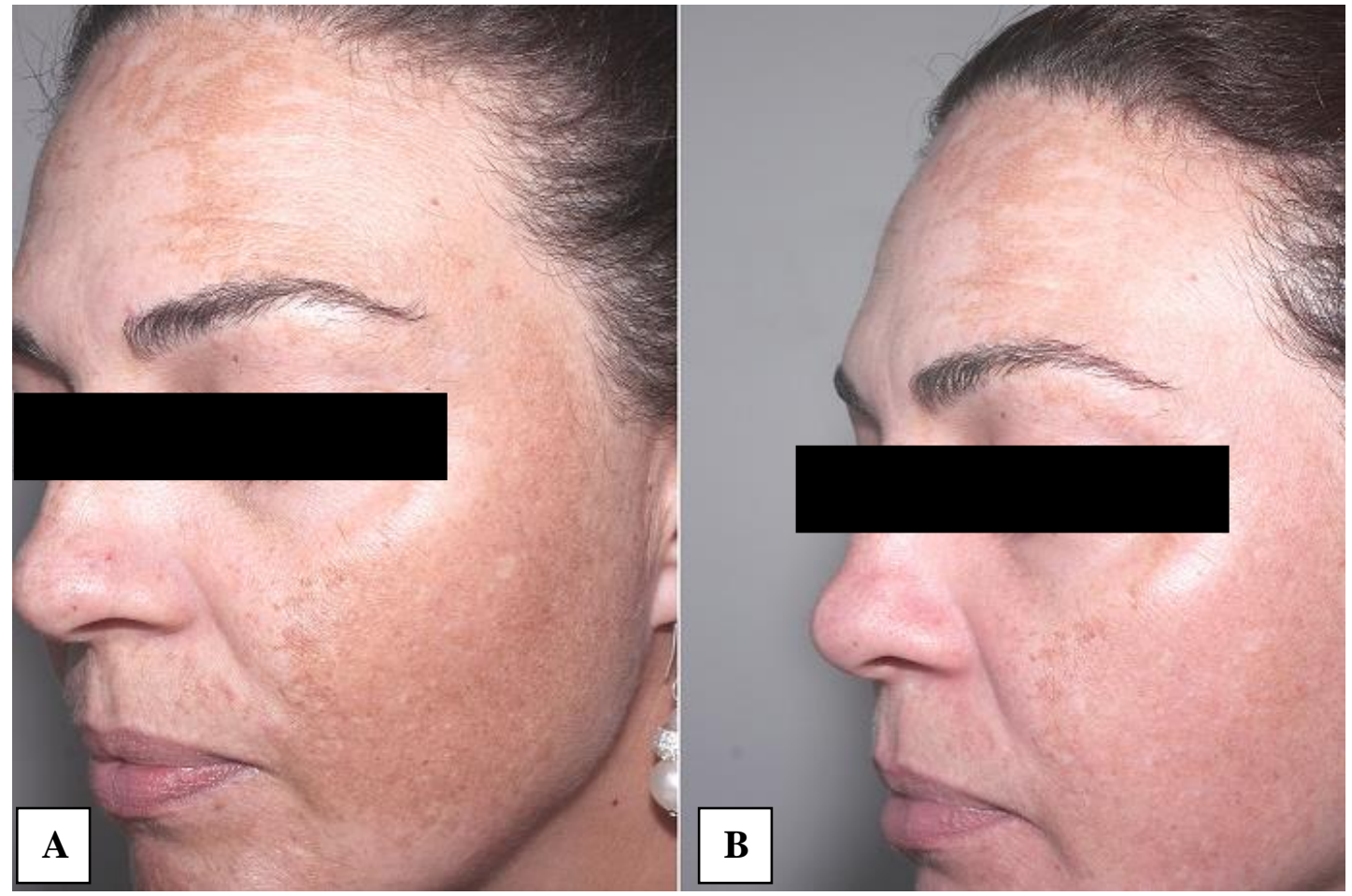

Figure 1. Melasma treated with QSNY, Before (A) and after (B) eight sessions of QSNY, 7-mm spot size, 600 mJ, 3 passes

using $2 \%$ hydroquinone alone. Each subject was treated with $3.0-3.8 \mathrm{~J} / \mathrm{cm}^{2}$ at $10 \mathrm{~Hz}$ for five sessions at one-week intervals. They observed that the degree of lightening on the laser-treated side was higher or equal to the control side. The mild side effects disappeared within an hour of the treatment, but three patients developed mottled hyperpigmentation (all with skin type V). Eight of 22 patients developed confetti-type hypopigmentation. Although the laser treatment was discontinued, all of the patients exhibited some degree of rebound hyperpigmentation $^{[19]}$. Gokalp and co-workers found the melasma recurrence rates from low-fluence 1064-nm QS laser was high after one-year follow-up (60\% of whom had responded well to the initial treatment ${ }^{[2]}$.

Melasma can be safely and successfully treated with sub-thermolytic 1064-nm QSNY therapy if correctly applied, and even low fluences $\left(1.6 \mathrm{~J} / \mathrm{cm}^{2}\right)$ can be effective to prevent complications. In order to obtain the best results, laser therapy should be combined with topical agents. Side effects are commonly transitory and mild, such as transient erythema and edema, which disappear within an hour ${ }^{[3]}$. One of the most serious side effects is hypopigmentation. High fluences inducing direct phototoxicity and cellular destruction of melanocyte, as well as subthreshold additive effect of various doses, intrinsic unevenness of skin pigmentation, and non-uniform laser energy output, could be possible pathogenic processes for this depigmentation ${ }^{[11,20]}$.

The QS Ruby laser (QSRL) at $694 \mathrm{~nm}$ is more selective for melanin than 1064-nm QSNY. However, its efficacy for melasma is controversial ${ }^{[8,9]}$. Hilton and co-workers treated 25 Caucasian women with melasma with $4-8 \mathrm{~J} / \mathrm{cm}^{2}$ and $1 \mathrm{~Hz}$ of frequency. Post-inflammatory hyperpigmentation (PIH) and recurring melasma were observed in $28 \%$ and $44 \%$ patients, respectively, after three-month follow-up ${ }^{[21]}$.

The 755-nm QS Alexandrite laser (QSAL) has so been applied for cutaneous pigmented lesions. A split-face study with 20 male and female subjects with moderate to severe mixed-type melasma was conducted to make a comparison between low-fluence QSNY 1064-nm and low-fluence QSAL 755-nm. The authors found that both low-fluence Q-switches were equally effective at improving facial melasma. In this study, on the QSAL-treated side, only 1-2 passes were required to reach the endpoint of mild erythema, while more than eight passes were sometimes needed to get the same endpoint with QSNY. In addition, no increased adverse events were seen with QSAL. Therefore, it is important not to overlap or accidentally pulse stack when using the QSAL, because it could overstimulate melanocytes more easily than the 1064-nm QSNY could ${ }^{[10]}$.

\section{Long-pulsed lasers}

Long-pulsed lasers (LPL), with pulse widths of micro- 
seconds to milliseconds, have been recently found to be effective for treating epidermal pigmentary lesions. Lee et al. treated 48 patients of melasma with two to four sessions of fractional, long-pulsed Alexandrite laser at two- to three-week intervals $\left(60-80 \mathrm{~J} / \mathrm{cm}^{2}, 15-\mathrm{mm}\right.$ spot size, 0.5-1.0-ms pulse width). Two months after finishing treatment, the mean modified melasma area and severity index score reduced significantly (16.5 vs. 11.5; $p$ $=0.002$ ). They determined that this modality of laser is moderately effective in dealing with melasma and it has low risk of adverse effects ${ }^{[22]}$.

The QS laser delivers high energy with a short pulse width and it causes not only photothermal but also photomechanical effects that can be transmitted to the normal skin, increasing the risk of PIH. On the other hand, LPL seems to have a gentler heating effect than QS. By decreasing the exposure energy to a level that would not cause epidermal injury, the LPL is effective for epidermal pigmentation through a purely photothermal effect $^{[23]}$.

A study on 360 Korean patients compared the effectiveness and safety of combination therapy using low-fluence QSNY and long-pulse Nd:YAG laser (dual toning) with treatment using low-fluence QSNY monotherapy. The results showed superior improvement and less adverse effects (1.1\% vs. $14.1 \%)$ in the dual toning $\operatorname{group}^{[23]}$.

\section{Non-ablative fractionated lasers}

Several among the lasers used for the treatment of melasma are non-ablative fractionated lasers (NAFL). Such devices are generally safer and do not cause many of the side effects of ablative systems. Fractional photothermolysis creates microthermal zones and leaves most of the treatment area intact. The intact skin aids in the healing process via the extrusion of necrotic debris and the migration of keratinocytes ${ }^{[11,23]}$. Although the use of NAFL has become popular, there are still very few evidence-based data supporting it in melasma therapy. Karsai and co-workers studied 51 patients, and their conclusions do not sustain the hypothesis of non-ablative $1550-\mathrm{nm}$ fractional laser providing a substantial benefit in treating melasma when compared to the broad-spectrum sunscreen application alone ${ }^{[8]}$. Barysch and co-workers treated 14 subjects in a split-face study with non-ablative fractioned photothermolysis $1540-\mathrm{nm}$ (320 MTZ/ $\mathrm{cm}^{2}, 15-\mathrm{ms}$ pulse length) in three sessions (weeks 0, 3-4, 6-8) and a follow-up (week 26-28). The results reached the highest pigment reduction after the first two sessions, although melasma partially recurred after 26-28 weeks from baseline. In addition, $17 \%$ of patients suffered from worsening le- sions because of PIH (skin types III and IV). The authors noticed that despite its lower side effects, NAFL requires prudence in darker skin types (III+) because of the PIH risk, and sessions should be performed, if any at all, with low densities ${ }^{[24]}$.

\section{Ablative fractionated lasers}

The Erbium-doped yttrium aluminium garnet (Er:YAG) laser emits light with a 2940-nm wavelength, which is highly absorbed by water. In addition, it ablates the skin with minimal thermal injury. Attwa et al. used the Er:YAG laser in 15 Egyptian female subjects with melasma who were refractory to bleaching creams and chemical peels. Recurrence of melasma was noticed in five patients and PIH was noticed three to six months after treatment began. The study found that 2940-nm Er:YAG ablative laser resurfacing effectively improved melasma; however, the PIH's transient appearance needs persistent and prompt intervention ${ }^{[25]}$.

Manaloto et al. reported improvement of melasma immediately after treatment with Er:YAG laser. Nevertheless, all patients developed PIH between three and six weeks post-operatively ${ }^{[26]}$. The occurrence of PIH limits the use of this laser for recalcitrant melasma ${ }^{[11]}$.

Trelles et al. evaluated 30 female (skin types II-IV), comparing treatment with topical anti-pigmenting cream alone (Kojic acid, glycolic acid, hydroquinone $2 \%$ ) vs. 10,600-nm fractional ablative $\mathrm{CO}_{2}$ resurfacing vs. 10,600-nm fractional ablative $\mathrm{CO}_{2}$ resurfacing and topical anti-pigmenting cream maintenance. Overall, efficacy in all three groups were $100 \%$ at one month but progressively declined in further assessment, except for the laser/topical anti-pigmenting cream group, which showed maintenance of improvement after 12 month follow-up ${ }^{[27]}$.

Fractional ablative laser alone cannot be considered highly effective for treating melasma, and in darker skin types, the risk of PIH is elevated. Ablative Er:YAG and $\mathrm{CO}_{2}$ lasers are generally safe for patients with Fitzpatrick skin types III-V, but the large rates of PIH require the use of adjunctive anti-pigmenting agents ${ }^{[12]}$.

\section{Intense pulsed light}

Intense pulsed light (IPL) devices utilize a flash lamp to generate non-coherent, high-energy, broad-spectrum light ranging from $500 \mathrm{~nm}$ to $1,200 \mathrm{~nm}$. Filters can be applied to increase target specificity. For epidermal sions, 500-550 $\mathrm{nm}$ filters are often used. Despite the refractory and recurrent nature of melasma, IPL is an effective treatment modality ${ }^{[8]}$. Zoccali et al. conducted 38 patients with melasma, working with cutoff filters of $550 \mathrm{~nm}$, pulse of 5-10 ms, pulse delay of 
$10-20 \mathrm{~ms}$ and low fluence of $6-14 \mathrm{~J} / \mathrm{cm}^{2}$, and reached $80 \%-100 \%$ clearance in $47 \%$ patients $^{[28]}$.

Choosing the correct IPL settings in the treatment plays an important role. The fluence can be adjusted in relation to the anatomic sites, and higher fluences are helpful for deeper lesions but induce PIH in dark-skinned patients ${ }^{[29]}$. Consequently, lower fluence should be used for higher phototypes. Single pulses heat pigment well, but double or triple pulses should be used, as they decrease the thermal damage by permitting the epidermis to cool while the target stays warm. It is thought that the delay time between pulses should not be less than 10 $\mathrm{ms}$ because it raises the risk of thermal damage as the targeted tissue cannot diminish its temperature within that time. More sessions are necessary for maintenance and to reduce the possibility of recurrence ${ }^{[11]}$.

Unlike conventional IPL system, Chung and co-workers found that pulse-in-pulse IPL mode (multiple fractionated subpulses within one pulse duration of $10 \mathrm{~ms}$ ) could be a secure and hopeful treatment for melasma, as it does not raise the temperature of the purposed tissue ${ }^{[30]}$.

Moreno Arias and Fernando found a clearance of $76 \%-100 \%$ for superficial lesions such as ephelides, café au lait macules, and epidermal melasma in their study of IPL and melanocytic lesions. Nevus spilus showed good clinical clearance (51\%-75\%); though deep lesions such as nevus of Becker, epidermal nevus, and mixed melasma showed an average clearance of less than $25 \%$. PIH was observed in melasma ${ }^{[31]}$.

Wang et al. compared 17 patients (Fitzpatrick skin types III-IV) with refractory melasma treated with IPL and $4 \%$ hydroquinone cream versus $4 \%$ hydroquinone cream alone. A 570-nm cutoff filter was utilized initially, and 590-615-nm filters later on, to reach deeper melanin. They performed four sessions at four-week intervals. Patients in the IPL group gained $39.8 \%$ improvement in relative melanin index, while there was an $11.6 \%$ improvement in the control group $(p<0.05)$ at week 16. Recurrence was observed in two patients from the IPL group 24 weeks after the last session ${ }^{[32]}$.

Although IPL is effective for epidermal melasma, it must be kept in mind that dermal or mixed melasma treated with higher fluences has the risk of $\mathrm{PIH}^{[33]}$. Also, sun protection and hydroquinone should accompany IPL to maintain results (Table 1).

\section{Picosecond lasers}

Many other options that could also help to improve results are being more accepted nowadays, including oral tranexamic acid, antioxidants, and laser-assisted drug delivery ${ }^{[34]}$. Several studies have been conducted to find the best way to treat melasma. Some technologies have been developed, aiming for good results and lower adverse effects on tissues. Q-switched lasers work through extremely fast pulses, typically 5 to 50 nanoseconds. Recently, technologies have been developed in pico- and femtoseconds, which have the advantage of penetrating deep tissue and of generating very high power, although the high energy is not required. So, low energy can be used, leading to smoother treatments and faster recuperation ${ }^{[35]}$.

Picosecond lasers (PSL) intend to treat skin conditions using high pulse energy and extremely short durations. At PSL pulse widths, acoustic stress can be larger than thermal stress, leading to more efficient fracturing for similar pulse energies, particularly for smaller pigmented particles. In addition, less pulse energy is required to achieve similar acoustic fracture pressures, resulting in reduced risk of scarring. Picosecond pulses confine the energy to the pigment particle more effectively, resulting in increased photoacoustic breakup of the target. This allows an effective treatment at lower fluences, thereby decreasing the thermal energy transferred to surrounding tissues. In pigmented lesions, the mechanism of action is predominantly the fragmentation of melanosomes and the scattering of the melanin particles ${ }^{[36]}$. Friedman treated 29 melasma patients of skin types II-IV, who were unsuccessfully treated with topical agents, with a large spot 532-nm Nd:YAG picosecond-domain laser. Subjects received 1-4 sessions spaced 3-5 weeks apart. Patients self-assessed their average improvement as $28 \%, 50 \%$, and $62 \%$ after the first, second, and third treatment, respectively. Those with skin type VI achieved an average of $60 \%$ improvement without $\mathrm{PIH}^{[37]}$.

As the energy-based device market matures, more studies will help to decide which devices and settings lead to optimal treatment improving outcomes.

\section{Conclusion}

Melasma is a pigment disorder difficult to be treated. The use of lasers to treat melasma must aim for minimal side effects and maximum efficacy. Choosing the appropriate energy-based device and correct settings is crucial (Table 2). Topical bleaching agents are still the gold standard of therapy because they are cheaper and more efficient when compared to lasers.

It is important that appropriate maintenance therapy is chosen to avoid recurrences. Cases unresponsive to topical therapy or chemical peels must be referred to laser-based treatment modalities. The combination of 
Table 1. Summary of clinical studies of IPL for melasma treatment ${ }^{[11]}$

\begin{tabular}{|c|c|c|c|c|c|c|c|c|c|}
\hline $\begin{array}{l}\text { Author/ } \\
\text { Year }\end{array}$ & $\begin{array}{l}\text { Type } \\
\text { of } \\
\text { study }\end{array}$ & $\begin{array}{l}\text { No. of } \\
\text { patients/ } \\
\text { skin type }\end{array}$ & $\begin{array}{l}\text { Type of } \\
\text { melasma }\end{array}$ & Laser & $\begin{array}{l}\text { Sittings/ } \\
\text { interval }\end{array}$ & Dose & Assessment & Results & $\begin{array}{l}\text { Side } \\
\text { effects }\end{array}$ \\
\hline $\begin{array}{l}\text { Wang et } \\
\text { al., } \\
2004^{[32]}\end{array}$ & $\mathrm{RCT}$ & 17/ III-IV & \multirow[t]{2}{*}{ Mixed } & $\begin{array}{l}\text { IPL + HQ } \\
\text { First session: } \\
570 \text { nm filter } \\
\text { Rest: } 590-615 \\
\text { nm filter }\end{array}$ & 4/4 week & $\begin{array}{l}\text { Fluence: } \\
26-33 \\
\mathrm{~J} / \mathrm{cm}^{2} \\
\text { Double } \\
\text { mode } \\
\text { Pulse } \\
\text { length: } \\
3-5 \mathrm{~ms} \\
\text { Delay: } \\
30-35 \\
\mathrm{~ms}\end{array}$ & Objective & $\begin{array}{l}\text { Excellent } \\
(76 \%-10 \\
0 \%): 12 \% \\
\text { Good } \\
(51 \%-75 \\
\%): 23 \% \\
\text { Fair } \\
(26 \%-50 \\
\%): 35 \% \\
\text { Poor } \\
(0-25 \%) \text { : } \\
30 \% \\
\text { Excellent: } \\
0 \% \\
\text { Good: } \\
14 \% \\
\text { Fair: } 7 \% \\
\text { Poor: } 79 \\
\%\end{array}$ & $\begin{array}{l}\text { Erythe- } \\
\text { ma, } \\
\text { pain, } \\
\text { PIH (2 } \\
\text { patients) }\end{array}$ \\
\hline $\begin{array}{l}\text { Zoccali } \\
\text { et al., } \\
2010^{[28]}\end{array}$ & & 38/ III-IV & & $\begin{array}{l}\text { IPL } \\
\text { Filter: } 550 \mathrm{~nm}\end{array}$ & $\begin{array}{l}3-5 / 40-45 \\
\text { days }\end{array}$ & $\begin{array}{l}\text { Fluence: } \\
6-14 \\
\mathrm{~J} / \mathrm{cm}^{2} \\
\text { Pulse: } \\
\text { 5-10 ms; } \\
\text { Delay: } \\
\text { 10-20 } \\
\mathrm{ms}\end{array}$ & Objective & $\begin{array}{l}\text { Excellent } \\
(80 \%-10 \\
0 \%): 47 \% \\
\text { Good } \\
(60 \%-79 \\
\%): 30 \% \\
\text { Moderate } \\
(40 \%-59 \\
\%): 13 \% \\
\text { Poor } \\
(<39 \%): \\
11 \%\end{array}$ & $\begin{array}{l}\text { No side } \\
\text { effects }\end{array}$ \\
\hline \multirow[t]{2}{*}{$\begin{array}{l}\text { Moreno } \\
\text { et al., } \\
2001^{[31]}\end{array}$} & & 5/ II-IV & $\begin{array}{l}\text { Epider- } \\
\text { mal }\end{array}$ & $\begin{array}{l}\text { IPL } \\
\text { Filter: } 590 \mathrm{~nm}\end{array}$ & $2 / 4$ weeks & $\begin{array}{l}\text { Fluence: } \\
6-14 \\
\mathrm{~J} / \mathrm{cm}^{2} \\
\text { Pulse: } \\
\text { 5-10 ms; } \\
\text { Delay: } \\
\text { 10-20 } \\
\mathrm{ms}\end{array}$ & $\begin{array}{l}\text { Subjective } \\
\text { only }\end{array}$ & $\begin{array}{l}76 \%-100 \\
\% \\
\text { clearance }\end{array}$ & - \\
\hline & & & Dermal & Filter: $615 \mathrm{~nm}$ & $4 / 8$ weeks & $\begin{array}{l}\text { Fluence: } \\
6-14 \\
\mathrm{~J} / \mathrm{cm}^{2} \\
\text { Pulse: } \\
5-10 \mathrm{~ms} ; \\
\text { Delay: } \\
\text { 10-20 } \\
\mathrm{ms}\end{array}$ & & $\begin{array}{l}<25 \% \text { cle } \\
\text { arance }\end{array}$ & $\mathrm{PIH}$ \\
\hline
\end{tabular}

IPL: Intense pulsed light

HQ: Hydroquinone

PIH: Post-inflammatory hyperpigmentation 
Table 2. Advantages and disadvantages of technologies for the treatment of melasma

\begin{tabular}{|c|c|c|}
\hline Technologies & Advantages & Disadvantages \\
\hline Q-switched lasers & $\begin{array}{l}\text { Photothermal and photoacoustic effect } \\
\text { Takes to melanin destruction without skin ablation }\end{array}$ & Risk of PIH \\
\hline QSNY & $\begin{array}{l}\text { Immediate side effects mild and transitory } \\
\text { Destroys exclusively the pigment }\end{array}$ & Risk of PIH \\
\hline QSRL & More selective for melanin than others QS & Risk of PIH \\
\hline QSAL & Few passes are required to reach the endpoint & Risk of PIH \\
\hline $\begin{array}{l}\text { Long pulsed } \\
\text { lasers }\end{array}$ & $\begin{array}{l}\text { Photothermal effect only } \\
\text { Without epidermal ablation }\end{array}$ & Less risk of PIH than QS \\
\hline NAFL & Creates microthermal zones without ablative effect & $\begin{array}{l}\text { Risk of PIH } \\
\text { Few data supporting its use } \\
\text { in melasma }\end{array}$ \\
\hline AFL & Ablates the skin with minimal thermal injury & High risk of PIH \\
\hline IPL & Filters can be applied to increase target specificity & Risk of PIH \\
\hline Picosecond lasers & $\begin{array}{l}\text { Reduced risk of scarring } \\
\text { Minimal downtime } \\
\text { Less pulse energy required }\end{array}$ & $\begin{array}{l}\text { Few data supporting its use } \\
\text { in melasma }\end{array}$ \\
\hline
\end{tabular}

QSNY: Q-switched Nd:YAG

QSRL: Q-switched Rubi Laser

QSAL: Q-switched Alexandrite

PIH: Post-inflammatory hyperpigmentation

QS: Q-switched

NAFL: Non-ablative fractioned laser

AFL: Ablative fractioned laser

IPL: Intense pulsed light

topical treatment and procedures are more effective than isolated treatments.

\section{Conflict of interest}

JM Jordão reports non-financial support from Vydence Medical, outside of the submitted work. Both authors declare no potential conflict of interest with respect to the research, authorship and/or publication of this article.

\section{References}

1. Kar HK, Gupta L, Chauhan A. A comparative study on efficacy of high and low fluence Q-switched Nd:YAG laser and glycolic acid peel in melasma. Indian J Dermatol Venereol Leprol 2012; 78(2): 165-171. doi: 10.41 03/0378-6323.93633.

2. Gokalp H, Akkaya AD, Oram Y. Long-term results in low-fluence 1064-nm Q-Switched Nd:YAG laser for melasma: Is it effective? J Cosmet Dermatol 2016; 15(4):
420-426. doi: 10.1111/jocd.12253.

3. Bevec T. Treating melasma with sub-thermolytic Q-switched Nd:YAG. J LAHA 2011; 2011(1): 53-55.

4. Kwon SH, Hwang YJ, Lee SK, Park KC. Heterogeneous pathology of melasma and its clinical implications. Int J Mol Sci 2016; 17(6): 824. doi: 10.3390/ijms 17060824.

5. Sofen B, Prado G, Emer J. Melasma and post inflammatory hyperpigmentation: Management update and expert opinion. Skin Therapy Lett 2016; 21(1): 1-7.

6. Majid I, Haq I, Imran A, Keen A, Aziz K, et al. Proposing melasma severity index: A new, more practical, office-based scoring system for assessing the severity of melasma. Indian J Dermatol 2016; 61(1): 39-44. doi: 10.4103/0019-5154.174024.

7. Rodrigues M, Pandya AG. Melasma: Clinical diagnosis and management options. Australas J Dermatol 2015; 56(3): 151-163. doi: 10.1111/ajd.12290.

8. Karsai S, Fischer T, Pohl L, Schmitt L, Buhck H, et al. Is non-ablative 1550 -nm fractional photothermolysis an ef- 
fective modality to treat melasma? Results from a prospective controlled single-blinded trial in 51 patients. $\mathrm{J}$ Eur Acad Dermatol Venereol 2012; 26(4): 470-476. doi: 10.1111/j.1468-3083.2011.04100.x.

9. Lee BW, Schwartz RA, Janniger CK. Melasma. G Ital Dermatol Venereol 2017; 152(1): 36-45. doi: 10.23736/S0392-0488.16.05425-0.

10. Fabi SG, Friedmann DP, Massaki ABN, Goldman MP. A randomized, split-face clinical trial of low-fluence Q-switched neodymium-doped yttrium aluminum garnet $(1,064 \mathrm{~nm})$ laser versus low-fluence Q-switched alexandrite laser $(755 \mathrm{~nm})$ for the treatment of facial melasma. Lasers Surg Med 2014; 46(7): 531-537. doi: 10.1002/lsm.22263.

11. Arora P, Sarkar R, Garg VK, Arya L. Lasers for the treatment of melasma and post-inflammatory hyperpigmentation. J Cutan Aesthet Surg 2012; 5(2): 93-103. doi: 10.4103/0974-2077.99436.

12. Tian WC. Novel technique to treat melasma in Chinese: The combination of 2940-nm fractional Er:YAG and 1064-nm Q-switched Nd:YAG laser. J Cosmet Laser Ther 2016; 18(2): 72-74. doi: 10.3109/14764172.2015.10636 62.

13. Dunbar S, Posnick D, Bloom B, Elias C, Zito P, et al. Energy-based device treatment of melisma: An update and review of the literature. J Cosmet Laser Ther 2017; 19(1): 2-12. doi: 10.1080/14764172.2016.1229485.

14. Jang YH, Park JY, Park YJ, Kang HT. Changes in melanin and melanocytes in mottled hypopigmentation after low-fluence 1,064-nm Q-switched Nd:YAG laser treatment for melasma. Ann Dermatol 2015; 27(3): 340-342. doi: 10.5021/ad.2015.27.3.340.

15. Kauvar ANB. Successful treatment of melasma using a combination of microdermabrasion and Q-switched Nd:YAG lasers. Lasers Surg Med 2012; 44(2): 117-124. doi: $10.1002 / 1 \mathrm{sm} .21156$.

16. Chen YT, Chang CC, Hsu CR, Shen JH, Shih CJ, et al. Combined vitamin $\mathrm{C}$ sonophoresis and neodymium-doped yttrium aluminum garnet (NdYAG) laser for facial hyperpigmentation: An outcome observation study in Asian patients. Indian J Dermatol Venereol Leprol 2016; 82(5): 587. doi: 10.4103/0378-6323.182806.

17. Parra CAH, Careta MF, Valente NYS, de Sanches Osório NEG, Torezan LAR. Clinical and histopathologic assessment of facial melasma after low-fluence QS Nd:YAG laser. Dermatol Surg 2016; 42(4): 507-512. doi: 10.1097/DSS.0000000000000653.

18. Jeong SY, Shin JB, Yeo UC, Kim WS, Kim IH. Low-fluence Q-switched neodymium-doped yttrium aluminum garnet laser for melasma with pre- or post-treatment triple combination cream. Dermatol Surg
2010; 36(6): 909-918. doi: 10.1111/j.1524-4725.20 10.01523.x.

19. Wattanakrai P, Mornchan R, Eimpunth S. Low-fluence Q-switched neodymium-doped yttrium aluminum garnet $(1,064 \mathrm{~nm})$ laser for the treatment of facial melasma in Asians. Dermatol Surg 2010; 36(1): 76-87. doi: 10.1111/j.1524-4725.2009.01383.x.

20. Wong Y, Lee SSJ, Goh CL. Hypopigmentation induced by frequent low-fluence, large-spot-size QS Nd:YAG laser treatments. Ann Dermatol 2015; 27(6): 751-755. doi: 10.5021/ad.2015.27.6.751.

21. Hilton S, Heise H, Buhren BA, Schrumpf H, Bölke E, et al. Treatment of melasma in Caucasian patients using a novel 694-nm Q-switched ruby fractional laser. Eur J Med Res 2013; 18(1): 43. doi: 10.1186/2047-783 X-18-43.

22. Lee MK, Min KS, Park EJ, Kim KH, Kim KJL. A retrospective analysis of the treatment of melasma using a fractional long-pulsed alexandrite laser in Korean patients. Dermatol Surg 2016; 42(8): 952-960. doi: 10.1097/D SS.0000000000000767.

23. Choi CP, Yim SM, Seo SH, Ahm HH, Kye YC, et al. Retrospective analysis of melasma treatment using a dual mode of low-fluence Q-switched and long-pulse Nd-YAG laser vs. low-fluence Q-switched Nd:YAG laser monotherapy. J Cosmet Laser Ther 2015; 17(1): 2-8. 10.3109/14764172.2014.957217.

24. Barysch MJ, Rümmelein B, Kolm I, Karpova MB, Schönewolf N, et al. Split-face study of melasma patients treated with non-ablative fractionated photothermolysis (1540 nm). JEADV 2012; 26(4): 423-430. doi: 10.1111/j.1468-3083.2011.04086.x.

25. Attwa E, Khater M, Assaf M, Haleem MA. Melasma treatment using an erbium:YAG laser: A clinical, immunohistochemical, and ultrastructural study. Int J Dermatol 2015; 54(2): 235-244. doi: 10.1111/ijd.12477.

26. Manaloto RM, Alster T. Erbium:YAG laser resurfacing for refractory melasma. Dermatol Surg 1999; 25(2): 121-123. doi: 10.1046/j.1524-4725.1999.08103.x.

27. Trelles M, Velez M, Gold M. The treatment of melasma with topical creams alone, $\mathrm{CO} 2$ fractional ablative resurfacing alone, or a combination of the two: A comparative study. J Drugs Dermatol 2010; 9(4): 315-322.

28. Zoccali G, Piccolo D, Allegra P, Giuliani M. Melasma treated with intense pulsed light. Aesthetic Plast Surg 2010; 34(4): 486-493. doi: 10.1007/s00266-010-9485-y.

29. Na SY, Cho S, Lee JH. Intense pulsed light and low-fluence Q-switched Nd: YAG laser treatment in melasma patients. Ann Dermatol 2012; 24(3): 267-273. doi: 10.5021/ad.2012.24.3.267.

30. Chung JY, Choi M, Lee JH, Cho S, Lee JH. Pul- 
se-in-pulse intense pulsed light for melasma treatment: A pilot study. Dermatol Surg 2014; 40(2): 162-168. doi: 10.1111/dsu.12414.

31. Moreno Arias GA, Fernando J. Intense pulsed light for melanocytic lesions. Dermatol Surg 2001; 27(4): 397-400. doi: 10.1046/j.1524-4725.2001.00315.x.

32. Wang CC, Hui CY, Sue YM, Wong WR, Hong SH. Intense pulsed light for the treatment of refractory melasma in Asian persons. Dermatol Surg 2004; 30(9): 1196-1200. doi: 10.1111/j.1524-4725.2004.30371.x.

33. Bae MI, Park JM, Jeong KH, Lee MH, Shin MK. Effectiveness of low-fluence and short-pulse intense pulsed light in the treatment of melasma: A randomized study. J Cosmet Laser Ther 2015; 17(6): 292-295. doi: 10.3109/14764172.2015.1027228.

34. Robinson DM, Friedman PM, Li JY, Geddes ER. A review of melasma treatment focusing on laser and light devices. Semin Cutan Med Surg 2016; 35(4): 223-232. doi: 10.12788/j.sder.2016.060.

35. Kalil C, Campos V. Manual prático do laser e outras fontes de energia eletromagnética na dermatologia (Portuguese) [Practical manual of laser and other electromagnetic energy sources in dermatology]. 1st ed. Rio de Janeiro, Brazil: Elsevier; 2017.

36. Tanghetti EA. The histology of skin treated with a picosecond alexandrite laser and a fractional lens array. Lasers Surg Med 2016; 48(7): 646-652. doi: 10.10 02/1sm.22540.

37. Friedman D. Novel method for treatment of melasma with a 532nm picosecond laser. In: 2016 Late-Breaking Abstracts. Lasers Surg Med 2016; 48(4): 421. doi: 10.1002/lsm.22526. 